\title{
Interconnectedness and systemic risk measures of Chinese financial institutions
}

\author{
Ming Qi \\ School of Economics and Management, China University of Petroleum (Beijing), \\ Beiing, China \\ Jiawei Zhang \\ Amsterdam Business School, University of Amsterdam, \\ Amsterdam, The Netherlands \\ Jing Xiao \\ School of Banking and Finance, University of International Business and Economics, \\ Beijing, China, and \\ Pei Wang, Danyang Shi and Amuji Bridget Nnenna \\ School of Economics and Management, China University of Petroleum (Beijing), \\ Beijing, China
}

\begin{abstract}
Purpose - In this paper the interconnectedness among financial institutions and the level of systemic risks of four types of Chinese financial institutions are investigated.

Design/methodology/approach - By the means of RAS algorithm, the interconnection among financial institutions are illustrated. Different methods, including Linear Granger, Systemic impact index (SII), vulnerability index (VI), CoVaR, and MES are used to measure the systemic risk exposures across different institutions.

Findings - The results illustrate that big banks are more interconnected and hold the biggest scales of interbank transactions in the financial network. The institutions which have larger size tend to have more connection with others. Insurance and security companies contribute more to the systemic risk where as other institutions, such as trusts, financial companies, etc. may bring about severe loss and endanger the financial system as a whole.

Practical implications - Since other institutions with low levels of regulation may bring about higher extreme loss and suffer the whole system, it deserves more attention by regulators considering the contagion of potential risks in the financial system.

Originality/value - This study builds a valuable contribution by examine the systemic risks from the perspectives of both interconnection and tail risk measures. Furthermore; Four types financial institutions are investigated in this paper.
\end{abstract}

Keywords Systemic risk, Interconnectedness, Centralities, Statistical measures

Paper type Research paper

\section{Introduction}

The definition of systemic risk varies depending on the understanding of the system and the recognition of risk elements. This risk, however, is widely believed to be the possibility that

(C) Ming Qi, Jiawei Zhang, Jing Xiao, Pei Wang, Danyang Shi and Amuji Bridget Nnenna. Published by Emerald Publishing Limited. This article is published under the Creative Commons Attribution (CC BY 4. 0) licence. Anyone may reproduce, distribute, translate and create derivative works of this article (for both commercial and non-commercial purposes), subject to full attribution to the original publication and authors. The full terms of this licence may be seen at $\mathrm{http} / /$ creativecommons.org/licences/by/4.0/legalcode

This research is granted by the National Social Science Fund of China (20BJY233). nectedness and systemic risks 
$\mathrm{K}$

51,13

the failure of one financial institution could cause other interconnected institutions to be in distress, and harm the economy as a whole (Amalia, 2018). Because systemic risk impacts all market players and cannot be eliminated by diversification, the whole financial system may suffer dramatic fluctuations once an important institution collapse. Taking the 2008 global financial crisis as an example, the subprime mortgage crisis in the United States plagued the global financial system through multiple channels such as relative information, liquidity, risk premium, direct linkages, and asset holdings commonality (Kiyotaki et al., 1997; Longstaff, 2010; Caccioli, 2014; Amalia, 2018). It also caused a considerable loss of financial companies, commercial banks, and several security firms. Therefore, the stability of the financial system deserves a detailed investigation.

There are four major types of institutions in China's financial sector: banks, securities and insurance firms, and other institutions. Other institutions refer to financial companies, microcredit companies, financial guarantee companies, pawn houses, financial leasing companies, commercial factoring companies, and asset management companies. All these institutions are not supervised by any centralized authority [1]. Instead, they are supervised by local financial supervision and administration office. Therefore, there exists higher risks in these types of financial institutions [2]. Banks receive the greatest attention from scholars among all institutions, whereas others are less studied. Although banks continue to be the dominant in Chinese financial system, non-bank financial institutions play an essential role in the present. Securities, insurance, and other non-bank financial companies have grown in size and prominence in recent decades as the financial industry has evolved. Figure 1 (a) shows that the ratio of total annual assets of insurance and security firms to total financial yearly assets has risen from $10.9 \%$ in 2012 to 31.8 $\%$ in 2018. The average annual assets of other financial institutions, such as trust and fund firms, increased fast from 2.08 billion in 2012 to 53.96 billion in 2018.

Some international banks and non-bank institutions, including insurance firms, security firms, investment management organizations, and trusts, participated intensively in the Chinese interbank market. All of the institutions mentioned above have already established themselves as essential components of China's financial system. Therefore, it is reasonable to include more types of institutions to explore the risk contagion. In addition, insurance and security companies contribute a significant proportion of total fund transactions in terms of the interbank market. As shown in Figure 1 (b), the average interbank lending of insurance and securities account for $30.7 \%$ in 2012 and $32.4 \%$ in 2016. Considering the large volume of interbank transactions, it is essential to include non-bank financial institutions when assessing systemic risk. The main contribution of this study is to involve non-bank institutions as important actors in the financial network and measure the systemic risks of these organizations quantitatively. This study bridges the research gap between network theory and systemic risk metrics within the Chinese financial system, which includes different types of financial institutions. We employ the RAS algorithm to obtain the bilateral exposure matrix and use different statistical measures to evaluate the systemic risk exposures. This study provides answers to two research questions. Firstly, what is the degree of centrality of the Chinese financial network, and to what extent are the financial institutions interconnected? Secondly, what are the systemic risk measures of different types of financial institutions in Chinese financial system? The systemic important financial institutions within China's financial network are identified by different measures. The findings reveal that banks have the most interconnections in the network, followed by insurance firms, securities, and other institutions. Insurance and security firms contribute more systemic risks than other institutions. Securities have fewer interconnections in the market, but their potential losses are predicted to be more than banks. Other financial institutions may incur even more significant losses in the event of a risk. The remainder of this paper is organized as follows: Section 2 discusses relevant literature on systemic risk. Section 3 estimates the bilateral exposures matrix and outlines the systemic risk measures. Section 4 examines the network 


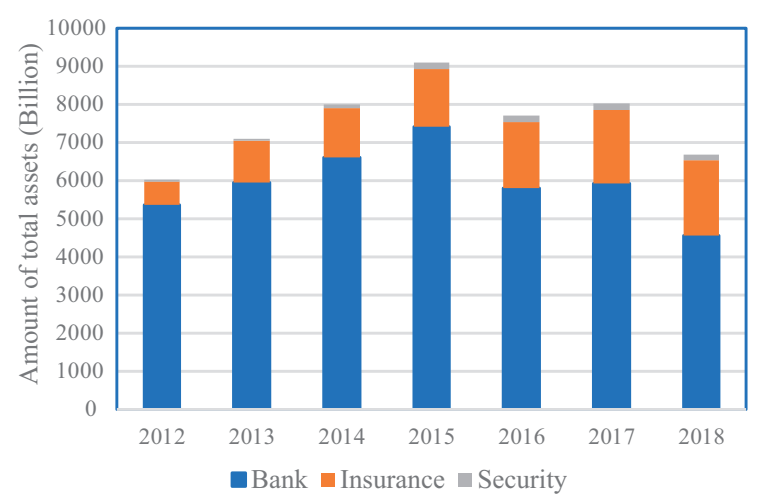

Interconnectedness and systemic risks

Total assets of Financial Institutions

(a)

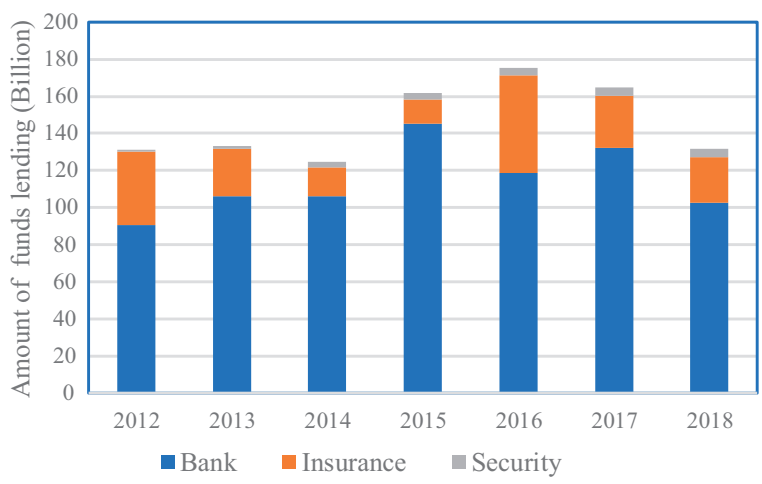

Interbank Lending of Financial Institutions

(b)

Figure 1.

(a): Total assets of Financial Institutions (b): Interbank Lending of Financial Institutions

structure and assesses the financial network's level of systemic risk. The last section finishes with a discussion of policy consequences.

\section{Literature review}

According to the review of systemic risk literature by Silva (2017), the definition of systemic financial risk remains unclear. The European Central Bank defined systemic risk as the possibility of an institution failing to honor its obligations, prompting the same failure on the part of other participants (ECB, 2009). De Bandt and Hartmann (2000) proposed that a systemic crisis can be defined as a systemic event that affects a considerable number of financial institutions or markets in a strong sense, thereby severely impairing the general well-functioning of the financial system. Although without explicit definition, a series of methods have been developed to measure the systemic risk in recent years (Huang et al., 2017; Bisias et al., 2012; Acharya et al., 2010). Martínez-Jaramillo et al. (2010) argues that financial contagion is a central concept in the study of systemic risk because this mechanism helps to explain why financial instability becomes so widespread. Other mechanisms might be the unwinding of financial imbalances and the occurrence of severe macro shocks. The contagion 
$\mathrm{K}$

51,13

60

can be defined as the probability that the instability of the given institution will spread to other parts of the financial system with adverse effects, leading to system-wide stress (Smaga, 2014). In terms of the Chinese financial system, some researchers have found that international trade, international capital flow, attention disposition in the banking industry, and real estate industry could be the contagion channels (Wu, 2014; Xiao, 2014). Current researches mainly focus on the contagion among commercial banks. Four contagion mechanisms are discussed in previous research: Solvency reduction, financial assets value decline, liquidity decline, and financial constraint (Brunnermeier and Pedersen, 2009; LopezEspinosa et al., 2015).

A series of methods have been developed to measure systemic risk based on the above mechanisms. Bisias et al. (2012) introduced 31 measures, most of which depend on the balance sheet data. The statistical model analysis is a common method proposed in recent studies, including Correlation coefficient analysis, VAR model, and so on. The Correlation coefficient analysis method reflects the possibility of risk contagion among different markets by examining the correlation among the variables. This method is intuitive and straightforward, but it requires a linear relationship between financial markets,which is a limitation. (Tjøstheim et al., 2013; Støve, 2014). The value-at-risk (VAR) model can solve problems such as endogenous variables and heteroscedasticity. But the shortcoming is that it cannot conduct dynamic analysis of relevant characteristics between financial markets. An alternative is the dynamic tail analysis method, which calculates the capital proceeds through the statistical characteristics of financial institutions.

Huang (2017) selected four tail analysis measures to weigh the systemic risk: Conditional Value at Risk (CoVaR), the marginal expected shortfall (MES), the systemic impact index (SII) and the vulnerability index (VI). As an extension of Value of Risk (VaR), CoVaR and $\Delta$ CoVaR, proposed by Adrian and Brunnermeier (2016), measures the systemic contribution of institutions conditional on other institutions experiencing financial distress. There are three major estimation models for CoVaR: quantile regression, DCC-GARCH model, and Copula model (Drakos and Kouretas, 2015; Bernardi et al., 2017; Trabelsi et al., 2017). Xu (2019) and Li (2019) uses LASSO-CoVAR and DCC-GARCH-CoVAR to investigate the risk spillover channels and the firm-level driving factors of the systemic risk in the Chinese banking sector, separately. On the other hand, Ji (2018) and Sun et al. (2020) use Copula-CoVAR to assess the systemic risk in the commodities markets. Similarly, systemic impact index (SII) and vulnerability index (VI) by Zhou (2010) measures the spillover effects to market when the institutions are faced with distress. They are the expansion of systemic expected shortfall (SES) by Acharya et al. (2010). MES evaluates the contribution of an institution to total capital shortfall of the whole system. Amalia (2018) pointed out that volatility during periods of prosperity is typically lower than in periods of distress. All statistical measures depend on market volatility. However, conditioning on extreme losses, these measures underestimate correlation contribution to systemic risk during non-crisis periods. Linear Granger causality test based on asset returns can directly measure interconnectedness through the stock market channel. The risk contagion model is suitable for investigating the interconnectedness of institutions since the dynamic risk propagation process can be simulated by the model (Paltalidis et al., 2015; Sun et al., 2020).

Other methods such as contingent equity analysis measure the systemic risk of expected losses implied by the market and estimate the liabilities of government under the condition of systemic distress. This method can not only measure the potential risk transferring from the financial sector to the government. Still, it can also identify the contribution of individual financial institutions to the government's contingent debt (Kritzman et al., 2010). Moreover, multivariate density estimation, which derives the multidimensional density function of a financial system. The systematic risk can be estimated by multidimensional density function, including the joint probability of default $(\mathrm{JPOD})$, financial stability index (FSI), dilemma dependency matrix (DDM), 
and chain reaction probability (Segoviano Basurto and Goodhart, 2009). The main contribution of this paper lies in the application of multiple measures not only to banks but also to all kinds of financial institutions. The systemic risk of different types of institutions in China is compared. Meanwhile, we combine the interconnectedness measures with tail analysis to reflect both the depth and breadth of risk spread in the Chinese financial market.

\section{Methodology}

The linear Granger-causality test is used to capture the correlation of financial institutions by identifying their stock return shock causality in order to quantify their interconnectedness. It can estimate the dynamic propagation of one institution in the financial system (Mensah and Premaratne, 2017). The degree of correlation can be used to evaluate the scope of systemic risks in the financial system. Losses of distressed institutions represent the market's and institutions' susceptibility to economic shocks, which gauges the extent of systemic vulnerabilities. To quantify the possibility and magnitude of financial loss, four statistical methods are employed to calculate the tail risk. First, when one institution experiences financialdistress, CoVaR and SII can assess the negative spillover consequences. CoVaR estimates the marginal contribution of individual institutions to systemic risk, whereas SII measures the expected number of bank failures if one institution fails. Second, marginal expected shortfall (MES) and vulnerability index (VI) estimate the losses and probability of failure of an institution when the whole financial system is in distress. All these methods are widely adopted by academia and regulators (Huang, 2017; Zhou, 2010).

\subsection{Interconnectedness analysis}

3.1.1 The network structure of the Chinese interbank market. In order to investigate the interconnects among financial institutions and obtain the degree of risk exposure, it is necessary to build a debt credit network. Referring to Kanno (2015) and Paltalidis et al. (2015), assuming that there are $N(N>2)$ financial institutions in the network. Hence the lending relationship in the interbank market can be represented by the $N \times N$ matrix as follows.

$$
X=\left[\begin{array}{c|ccccc}
a_{1} & x_{11} & \cdots & x_{1 j} & \cdots & x_{1 N} \\
\vdots & \vdots & \ddots & \vdots & \ddots & \vdots \\
a_{i} & x_{i 1} & \cdots & x_{i j} & \cdots & x_{i N} \\
\vdots & \vdots & \ddots & \vdots & \ddots & \vdots \\
a_{N} & x_{N 1} & \cdots & x_{N j} & \cdots & x_{N N} \\
\Sigma_{i} & l_{1} & \cdots & l_{i} & \cdots & l_{N}
\end{array}\right]
$$

$X$ is a $N \times N$ matrix, with $x_{i j}$ denotes outstanding loans from the institution $i$ to institution $j$, at the same time also represents the borrowings of bank $j$ from bank $i$. All the diagonal elements in matrix $X$ are zero, and the remaining $N \times(N-1)$ elements are unknown. Since the total amount of annual borrowing and lending is only observed from the balance sheet, it is impossible to estimate the debt matrix without further information. In order to estimate the direct bilateral transactions among banks, a possible way is to choose a distribution to minimize the uncertainty. Therefore, we use the information entropy theory to select a distribution for the lending entry data $x_{i, j}$. Such that $a_{i}=\sum_{j=1}^{N} x_{i j}, l_{i}=\sum_{i=1}^{N} x_{i j}, a_{i}$ indicates the total amount of lending funds by financial institution $i$ to other institutions in a given year. $l_{i}$ indicates the total amount of funds financial institution $i$ borrowed from other financial institutions in a given 
$\mathrm{K}$

51,13

year. Further adjustment is used to reduce the uncertainty of information. $a_{i}$ and $l_{i}$ subject to the marginal distributions $f\left(a_{i}\right)$ and $f\left(l_{i}\right)$, while the matrix $X$ subjects to the joint probability distribution $f\left(a_{i}, l_{i}\right)$. Assuming that $f\left(a_{i}\right)$ and $f\left(l_{i}\right)$ are independently distributed, the matrix is normalized, thus $\sum_{i} a_{i}=\sum_{i} l_{i}=1$. Then we can get $x_{i j}=a_{i}{ }^{*} l_{i}$, which reflects the importance of bank $i$. Subsequently, since the bank does not borrow the money to itself, all diagonal elements are zero, the initial value $x_{i j}^{*}$ is obtained as follows (Kanno, 2015).

$$
x_{i j}^{*}=\left\{\begin{array}{cc}
0 & \forall i=j \\
a_{i} * l_{i} & i \neq j
\end{array}\right.
$$

In order to satisfy the constraint $a_{i}=\sum_{j=1}^{N} x_{i j}, l_{i}=\sum_{i=1}^{N} x_{i j}$, following Wells (2004), Upper (2011) and Kanno (2015), a new matrix is constructed to minimize the uncertainty. Then we can use the optimization problem as follows to solve the matrix $X$. The optimization problem is solved by the RAS algorithm, which is proposed by Censor and Zenios (1998).

$$
\begin{gathered}
\min \sum_{i=1}^{N} \sum_{j=1}^{N} x_{i j} \ln \left(\frac{x_{i j}}{x_{i j}^{*}}\right) \\
\text { s.t. } \sum_{j=1}^{N} x_{i j}=a_{i}, \sum_{i} a_{i}=1 \\
\sum_{i=1}^{N} x_{i j}=l_{j}, \sum_{j} l_{j}=1
\end{gathered}
$$

In order to solve the optimization problem, we employ the RAS algorithm and get the Lagrange equation as follows,

$$
\mathrm{L}(x, \lambda, \mu)=\sum_{i=1}^{N} \sum_{j=1}^{N} x_{i j} \ln x_{i j}-\sum_{j=1}^{N} \lambda_{j}\left(\sum_{j=1}^{N} x_{i j}-a_{i}\right)-\sum_{i=1}^{N} \mu_{i}\left(\sum_{i=1}^{N} x_{i j}-l_{j}\right)
$$

thus $x_{i j}, \lambda_{i}, \mu_{j}$ can be obtained as follows:

$$
\left\{\begin{array}{l}
x_{i j}=\exp \left\{\lambda_{i}-0.5\right\} \cdot \exp \left\{\mu_{j}-0.5\right\} \\
\exp \left\{\lambda_{i}-0.5\right\} \cdot \sum_{j=1}^{N} \exp \left\{\mu_{j}-0.5\right\}=a_{i} \\
\exp \left\{\mu_{i}-0.5\right\} \cdot \sum_{j=1}^{N} \exp \left\{\lambda_{i}-0.5\right\}=l_{j}
\end{array}\right.
$$

The RAS algorithm should follow three steps to solve the matrix $X^{\prime}$ (Censor and Zenios, 1998; Kanno, 2015). Step 1: the row scaling: calculating of $\rho_{i j}^{k} x_{i j}^{k}$ to replace $x_{i j}^{k}$, with $\rho_{i j}^{k}=a_{i} / \sum_{\forall j \mid x_{i j}^{\prime}>0} x_{i j}^{k}$. Step 2: the column scaling: calculating $\sigma_{i j}^{k} x_{i j}^{k}$ to replace $x_{i j}^{k}$, with $\sigma_{i j}^{k}=l_{i} / \sum_{\forall i \mid x_{i j}^{\prime}>0} x_{i j}^{k}$. Step 3: $k=k+1$, and return back to step 1 . Then, we obtain the simulated matrix of interbank market loans and deposits of each institution, denoted as $a_{i}$ and $l_{i}$ respectively.

3.1.2 Network centrality of the financial system. We employed network centrality measures, such as Degree Centrality, Closeness Centrality, Betweenness Centrality, and 
PageRank Centrality, to properly represent the network structure of the financial market. These metrics are used to categorize node institutions according to their importance in the network.

3.1.2.1 Degree centrality. The network topology of China's financial market is a directed graph, that is, the connection between nodes is two-way. The network can be represented by a directed chart, $D=(N, A)$. Where $N$ denotes a set of all nodes, $A$ represents a set of all connections, and elements in matrix A, i.e $a_{i j}$, represent the existence of a lending relationship between node $i$ and node $j$. We calculate the in-Degree of the network node, that is, the amount of funds that each financial institution has borrowed from other institutions, and out-degree, that is, the amount of funds that each financial institution has to lend to other institutions, with $d_{i}^{-}$indicates node exit, $d_{i}^{+}$indicates node entry,

$$
d_{i}^{-}=\sum_{j \in N^{-}(i)} a_{i j} \quad \text { and } \quad d_{i}^{+}=\sum_{j \in N^{+}(i)} a_{i j}
$$

3.1.2.2 Closeness centrality. Closeness centrality calculates the sum of the distance of a given node to all other nodes in the financial network. A high closeness measure indicates the node institution is closest to other node institutions in the network and is spatially reflected in the central location. If $d\left(b_{i}, b_{j}\right)$ is used as the number of the shortest edge between institution $i$ and institution $j$, and the closeness centrality can be represented as follows,

$$
C\left(b_{i}\right)=n / \sum_{j=1}^{n} d\left(b_{i}, b_{j}\right)
$$

3.1.3 Betweenness centrality. Betweenness centrality calculates the number of shortest paths through a node. Thus, a node with high betweenness centrality can potentially influence the spread of information through the network. $p_{j k}$ represents the number of the shortest paths between node $j$ and $k$, and $p_{j k}(i)$ represents the number of shortest paths passing through node $i$ between node $j$ and node $k$, with

$$
B(i)=\sum_{j<k ; i \notin\{k, j\}} p_{j k}(i) / p_{j k}
$$

3.1.4 PageRank centrality. PageRank centrality comes from Google's PageRank algorithm. To ensure the integrity of information, the weight of inter-node connections, that is, the amount of risk exposure of financial institutions, must be considered in the inter-bank network. By introducing a diagonal matrix $D$ and $\alpha$ as the inverse of the eigen value less than the maximum $A D^{-1}$, the centrality is expressed as follows:

$$
x=\left(I-\alpha A D^{-1}\right)^{-1}=D \cdot(D-\alpha A)^{-1}
$$

\subsection{Linear Granger-Causality test}

The Linear Granger-causality test shows the connectivity and directionality of the relationship between variables (Granger, 1969). Following Billio et al. (2010), the Granger causality captures the lagged propagation of institutions' return spillover effect in the financial market. The model is denoted as follows:

$$
R_{t}^{x}=\sum_{i=1}^{q} a_{i} R_{t-i}^{x}+\sum_{i=1}^{q} b_{i} R_{t-i}^{y}+e_{t}^{x}
$$




$$
R_{t}^{y}=\sum_{i=1}^{q} c_{i} R_{t-i}^{x}+\sum_{i=1}^{q} d_{i} R_{t-i}^{y}+e_{t}^{y}
$$

$R_{t}^{x}$ and $R_{t}^{y}$ are returns of two different institutions on data $t, i$ ranges from 1 to $q$, that is, $R_{t-i}$ represents the lag length from 1 to $q . e_{t}^{x}$ and $e_{t}^{y}$ present two uncorrelated white noise processes. $b_{i}$ refers to the coefficient that determines the causality. If the null hypothesis is rejected, $R^{x}$ is predicted to have granger causality on $R^{y}$. Similarly, $R^{y}$ is predicted to have granger-causality on $R^{x}$ if $c_{i}$ is significantly different from zero. Then, we argue that the two institutions are interconnected with each other. If an institution has a higher number of causal relationships with others, it indicates that this institution will contribute more to system risk.

\subsection{SII and VI}

Systemic impact index (SII) and vulnerability index (VI) were proposed by Zhou (2010) as measures of systemic importance. Both indices are derived from the conditional probability of having at least one extra bank failure (PAO), which is presented as follows:

$$
P A O_{i}(p)=P\left(\left\{\exists j \neq i \text {, s.t } \quad X_{j}>\operatorname{VaR}_{j}(p)\right\} \mid X_{i}>\operatorname{VaR}_{i}(p)\right)
$$

When the expected number of failures is considered, SII can be defined as:

$$
\operatorname{SII}_{i}(p)=E\left(\sum_{j=1}^{d} 1_{X_{j}>V a R_{j}(p)}\left(X_{i}>V a R_{i}(p)\right)\right.
$$

$1_{A}$ is the indicator function. It equals 1 if $A$ holds, and is 0 otherwise. Thus, the probability of a particular bank failure when the system confronts distress can be measured by VI:

$$
V I_{i}(p)=P\left(X_{i}>\operatorname{VaR}_{i}(p) \mid\left\{\exists j \neq i \text {, s.t } X_{j}>\operatorname{VaR}_{j}(p)\right\}\right)
$$

Extreme Value Theory (EVT) is applied to calculate the value (Zhou, 2010). Suppose $\left(X_{1}, X_{2}, \ldots, X_{d}\right)$ follows the multivariate EVT setup, SII and VI can be calculated as:

$$
\begin{gathered}
\operatorname{SII}_{i}=\lim _{p \rightarrow 0} S I_{i}(p)=\sum_{j=1}^{d}\left(2-L_{i, j}(1,1)\right) \\
V I_{i}=\lim _{p \rightarrow 0} V I_{i}(p)=\frac{L_{\neq i}(1,1, \ldots, 1)+1-L(1,1, \ldots, 1)}{L_{\neq i}(1,1, \ldots, 1)}
\end{gathered}
$$

$L_{i, j}$ is the $L$ function characterizing the tail dependence of $\left(X_{i}, X_{j}\right)$. $\mathrm{L}$ function based on the historical data. $L(1,1, \ldots, 1)$ characterizes the tail dependence of $\left(X_{1}, \ldots, X_{d}\right)$ and $L_{\neq i}(1,1, \ldots, 1)$ characterizes $\left(X_{1}, \ldots, X_{i-1}, X_{i+1}, \ldots, X_{d}\right)$. The details about $L$ function were explained by De Haan and Ferreira (2006). It is necessary to replace the PAO measure with low-level $p . L(1,1, \ldots, 1)$ can be estimated as follows:

$$
\widehat{L}(1,1, \ldots, 1)=\frac{1}{k} \sum_{s=1}^{n} 1_{\exists 1 \leq i \leq d, \text { s.t. } X_{i s}>X_{i, n-k}}
$$

It is a practical and essential problem to choose the appropriate $k$ among the above estimators. Zhou (2010) advises calculating the estimator of $L(1,1, \ldots, 1)$ using different $k$. Then a line is plotted against the $k$ values. We are choosing $k$ in the first stable part of the line from low $k$ value. In this paper, SII and VI with different types of financial institutions are calculated. It is necessary to balance the deviation and variance of $k$ value when analyzing the data set. The problem is that $k$ value changes with group size and we want to compare the SII 
and VI of different types of institutions. Therefore, we control the $p$ level within each group identically. Thus, we choose $p=3.5 \%$ for each group and compute $k$ for them. In this paper, $k=125$ for banks; $k=386$ for Securities companies; $k=69$ for insurance companies; and $k=364$ for other institutions.

\subsection{CoVaR}

The $V a R_{q}^{i}$ is implicitly defined as the $q$ quantile of the return distribution. The $C o V a R_{q}^{j \mid i}$ is used to represent the $V a R$ of institution $j$ when it is conditional on returns of institution $i$. That is, $\mathrm{CoVaR}_{q}^{j \mid i}$ is implicitly defined by the $q$-quantile of the conditional probability distribution. According to Girardi and Tolga Ergün (2013), the definition of VaR and CoVaR is transferred to:

$$
\begin{gathered}
\operatorname{Pr}\left(R_{t}^{i} \leq \operatorname{VaR}_{q, t}^{i}\right)=q \\
\operatorname{Pr}\left(R_{t}^{j} \leq \operatorname{CoVaR}_{q, t}^{j \mid i} \mid R_{t}^{i}=\operatorname{VaR}_{q, t}^{i}\right)=q
\end{gathered}
$$

Where $R^{i}$ is the return of institution $i$. Note that $V a R_{q}^{i}$ is usually a negative number. This process has three advantages over Adrian and Brunnermeier (2016). Firstly, they allow us to consider more terms of institution $i$ that can be regarded as distressful. In addition, it improves the consistency of $\mathrm{CoVaR}$ with respect to the conditional dependence of the system on individual institutions (Mainik and Schaanning, 2014). Next, due to the time-varying correlation between an institution and financial system, they allow us to investigate the VaR and CoVaR over time, while they are assumed to keep constant in Adrian and Brunnermeier (2016). CoVaR can be used to determine the internal risk capital required by financial institutions to resist market risks as a whole. CoVaR can better reflect potential risks and is easier to calculate than VaR, so its application should be broader. In addition, the systemic risk contribution of a particular institution $j$ can be represented by $\Delta C_{o} V a R_{q}^{j \mid i}$. It is then calculated as the percentage difference of the VaR of the financial system conditional on the distressed state of institution $j$ $\left(R_{t}^{j} \leq \operatorname{VaR}_{q, t}^{j}\right)$. Adrian and Brunnermeier (2016) uses the median return of institution $i$ to replace a normal state of institution $i$, shown in equation (11).

$$
\Delta \operatorname{CoVaR}_{q}^{j \mid i}=\Delta \operatorname{CoVaR} R^{j \mid R_{t}^{i}=\operatorname{VaR}_{q}^{i}}-\Delta \operatorname{CoVaR}_{q}^{j \mid R_{t}^{i}=\operatorname{Median}^{i}}
$$

Following Girardi and Tolga Ergün (2013), the calculation of $\Delta C_{o} V a R_{q}^{j \mid i}$ can be divided into three steps. First, the VaR of each bank $i$ is calculated based on a GARCH $(1,1)$ model. Secondly, through the DCC $(1,1)$ model, the bivariate density of each bank is estimated. After the two steps above, the CoVaR is calculated by the expectation over the $q$-tail (with $q=0.05$ ). The benchmark state of institution $i$ is defined as $b^{i}$, i.e. $\mu_{t}^{i}-\sigma_{t}^{i} \leq R_{t}^{i} \leq \mu_{t}^{i}+\sigma_{t}^{i}$. The conditional probability distribution is calculated under the benchmark state $b^{i}$ by solving the dual integral equations:

$$
\begin{aligned}
& \int_{-\infty}^{C o V a R_{q, t}^{j i}} \int_{-\infty}^{V a R_{q, t}^{i}} p d f_{t}(x, y) d y d x=q^{2} \\
& \int_{-\infty}^{\mathrm{CoVaR}_{q, t}^{j b^{i}}} \int_{\mu_{t}^{i}-\sigma_{t}^{i}}^{\mu_{t}^{i}+\sigma_{t}^{i}} p d f_{t}(x, y) d y d x=p_{t}^{i} q
\end{aligned}
$$

where $p d f_{t}(x, y)$ is the joint probability density function of $x$ and $y$ at time $t$, and $p_{t}^{i}=P\left(\mu_{t}^{i}-\sigma_{t}^{i} \leq r_{t}^{i} \leq \mu_{t}^{i}+\sigma_{t}^{i}\right)$. Finally, $\Delta C_{o} V a R$ is the percentage difference between the $\mathrm{CoVaR}$ at the distressed state and the value at the benchmark state, as shown in equation (14). 
$\mathrm{K}$

51,13

It reflects the spillover effect from an institute to the system, indicating the percentage change of $V a R$ when an institute $j$ is in distress and in a normal state.

$$
\Delta \operatorname{CoVaR}_{q, t}^{j \mid i}=100 \times\left(\operatorname{CoVaR}_{q, t}^{j \mid i}-\operatorname{CoVaR}_{q, t}^{||^{i}}\right) / \operatorname{CoVaR}_{q, t}^{j \mid b^{i}}
$$

\subsection{MES}

Acharya et al. (2010) presents a statistical model to measure financial institution's contribution to the systemic risk and the expected loss when the market gets depressed substantially. Referring to the definition of $V a R$, the expected shortfall (ES) is calculated as the expected returns when the portfolio's loss exceeds its $V a R$ limit. It is defined as follows:

$$
E S_{\alpha}=E\left[R \mid R \leq V a R_{\alpha}\right]
$$

Marginal expected shortfall (MES) investigates the risk-taking behavior of financial institution $i$. In order to obtain this measure, $R$ is defined as the total return of the financial system and is decomposed into the sum of each groups' return $\left(r_{i}\right)$. That is $R=\sum_{i} y_{i} r_{i}$, where $y_{i}$ is the weight of bank $i$ in the financial system. Then we have:

$$
\begin{gathered}
E S_{\alpha}=\sum_{i} y_{i} E\left[r_{i} \mid R \leq V a R_{\alpha}\right] \\
M E S_{\alpha}^{i}=\frac{\partial E S_{\alpha}}{\partial y_{i}}=E\left[r_{i} \mid R \leq V a R_{\alpha}\right]
\end{gathered}
$$

MES measures the average return of any given institution during the $5 \%$ worst days for the overall market returns. It is estimated at a standard risk level of $\alpha=5 \%$ using daily equity returns from CRSP (Acharya et al., 2010):

$$
M E S_{i}=\frac{1}{\text { number of the } 5 \% \text { worst days }} \sum_{\text {t:system is in its } 5 \% \text { tal }} R_{t}^{i}
$$

This method is simple, but it may produce inaccurate results when some extreme events happen in the tail of the return distribution. It assumes that the probability of observing a conditioning event to be constant, which is not always the case. Since the volatility of financial time series is typically relatively high, it is more likely to observe losses beyond a given threshold. Brownlees and Engle (2016) suggests an alternative method for calculating MES which may solve these flaws. The volatility is estimated by GARCH models, in order to obtain the conditional volatility and standardized residuals. Then, a DCC specification is calculated to obtain the conditional correlation and the standardized idiosyncratic residual. The innovation of this model is the GARCH/DCC residuals. The one-period-ahead MES can be expressed as follows:

$$
M E S_{t-1}^{i \mid s}=\sigma_{i, t} \rho_{i s, t} E_{t-1}\left(\epsilon_{s, t} \mid \epsilon_{s, t} \leq \frac{V a R_{s, t}}{\sigma_{s, t}}\right)+\sigma_{i, t} \sqrt{1-\rho_{i s, t} 2} E_{t-1}\left(\epsilon_{s, t} \mid \epsilon_{s, t} \leq \frac{V a R_{s, t}}{\sigma_{s, t}}\right)
$$

Where $E(\cdot)$ denotes the tail expectation of the distribution of standardized innovations, $\rho_{i s}$ is the dynamic conditional correlation coefficient between institute $i$ and system $s, \sigma_{i}$ and $\sigma_{s}$ are time-varying conditional standard deviations. Since the GARCH/DCC model reports the dynamic conditional correlation and conditional standard deviations, it is only necessary to estimate the tail expectation of the distribution of standardized innovations. Following Brownlees and Engle (2016), we resort to a nonparametric kernel estimation approach to calculate the tail expectations, as shown in equation (20) 


$$
K_{h}(t)=\int_{-\infty}^{t / h} k(u) d u
$$

Where $k(u)$ is a kernel function and $h$ represents a positive bandwidth. Then,

$$
\widehat{E}_{h}\left(\epsilon_{s, t} \mid \epsilon_{s, t} \leq k\right)=\frac{\sum_{i=1}^{n} \epsilon_{s, t} K_{h}\left(\epsilon_{s, t}-k\right)}{n \widehat{p}_{h}}
$$

and

$$
\widehat{E}_{h}\left(\epsilon_{i, t} \mid \epsilon_{s, t} \leq k\right)=\frac{\sum_{i=1}^{n} \epsilon_{s, t} K_{h}\left(\epsilon_{s, t}-k\right)}{n \widehat{p}_{h}}
$$

Where $\widehat{p}_{h}=\frac{\sum_{i=1}^{n} K_{h}\left(\epsilon_{s, t}-k\right)}{n}$. MES measures the expected loss if the system is in distress, and reflects the vulnerability of individual institutions. $L R M E S_{t}^{i}$ is the Long Run MES, which is the expectation of arithmetic returns in multiperiod horizon. If the market extreme decline below a threshold occurs in time $l$, the LRMES is defined as:

$$
\operatorname{LRMES}_{t}^{i}=-E_{t}\left(R_{t+1: t+l}^{i} \mid R_{t+1: t+l}^{m}<C\right)
$$

where $R_{t+1: t+l}^{i}$ denotes the multiperiod arithmetic equity return between period $t+1$ and $t+l$.

\section{Data and results}

The financial statement data of Chinese banks, securities and other financial institutions are obtained from the BankFocus, which is provided by Bureau van Dijk (BvD) and Fitch. The time series stock returns are sourced from WIND, which is the leading financial data and information provider in mainland China. Our research is based on a set of 58 Chinese financial institutions which are classified into four categories: Banks, Security Dealers and Commodity Brokers (referred as Security), Insurance, and Other institutions. The CSI300 Index is used as a proxy for the financial system. The sampling period was between 1/4/2012 and 9/28/2018. 1,641 observations for each institution were used. VaR and CoVaR measures were computed at the $q=5 \%$ confidence level. Table 1 reports the VaR, CVaR $(C o V a R)$ and DCVaR $(\Delta C o V a R)$ of each category. The sample institutions are representative since the total assets account for about $64.72 \%$ of the financial market's total assets. The bank sample consists of 16 banks, including 5 State-Owned banks, 8 national-wide joint-stock banks and 3 city joint-stock commercial banks. The total assets account for more than $79 \%$ of all commercial banks' total assets.

\subsection{Interconnections in the financial network}

Granger causality test investigates the interconnections among financial institutions from the perspective of interaction of stock prices. The volatility of market value is one of the

\begin{tabular}{lccc}
\hline & Mean & Max & Min \\
\hline Banks & 24 & 69 & 4 \\
Securities companies & 16 & 32 & 3 \\
Insurance companies & 18 & 31 & 3 \\
Others institutions & 5 & 12 & 1
\end{tabular}

Table 1. The descriptive statistics of interconnections of financial institutions 
$\mathrm{K}$

51,13

68
Figure 2.

Chinese interbank connections network important manifestations of systemic risks. This method builds the granger causality network by measuring the number of interconnected institutions under certain confidence levels. Figure 2 depicts the network structure of the interbank market in 2014 and 2017 based
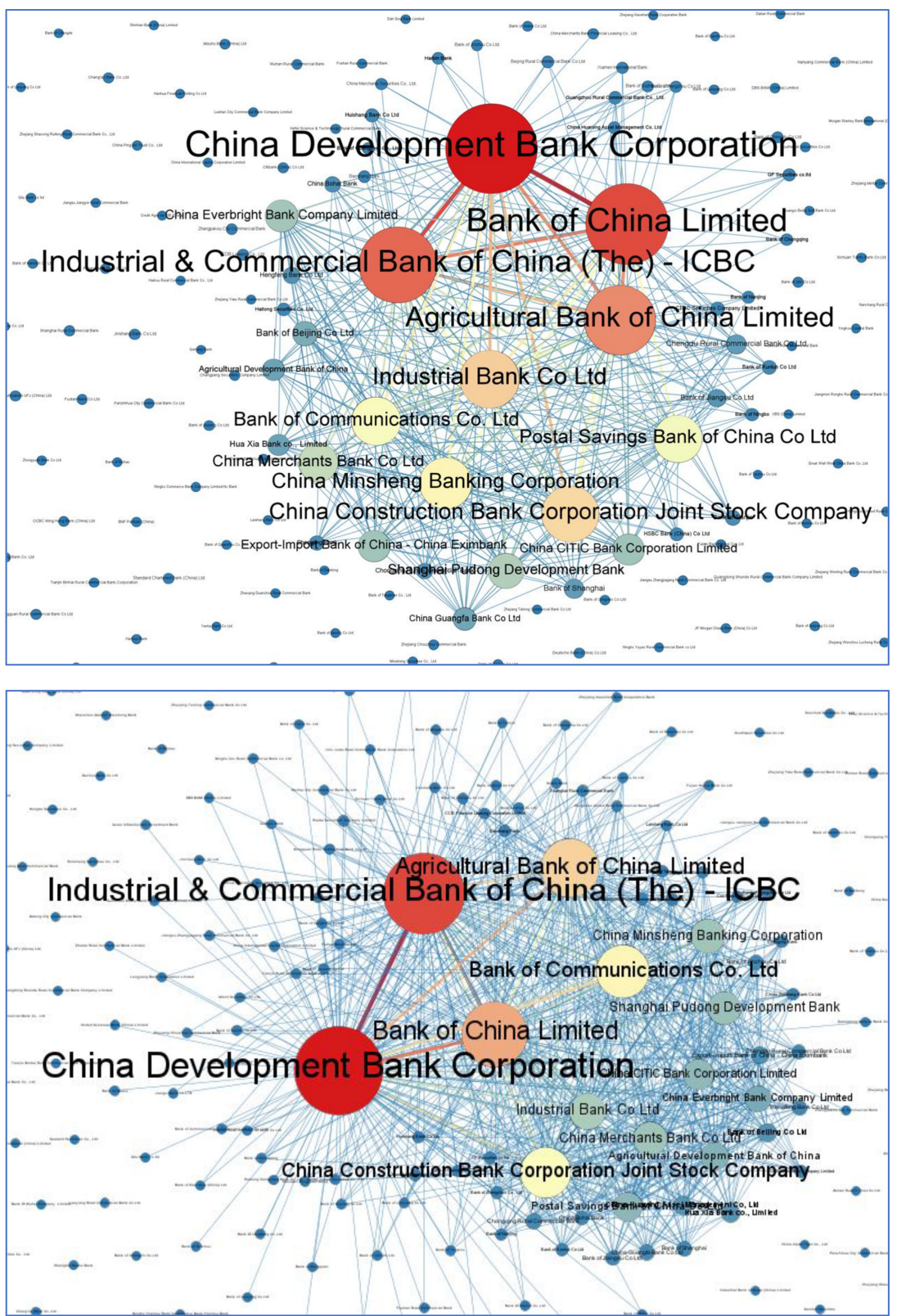

Note(s): Upper and lower graphs illustrate the interbank connections in the Chinese interbank market in 2014 and 2017 respectively 
on the interbank lending matrix. The bilateral exposure matrix $X$ is illustrated in a directed graph as shown in Figure 2. The upper and lower panels demonstrate the interconnections among all financial institutions in 2014 and 2017, respectively. The width of an edge denotes the inter-bank exposure size at the end of the year, and the color shows the mixing of its source node and target node. The size of the node denotes the number of connections of individual financial institution (Kanno, 2015). Big banks are more interconnected and have the most extensive inter-bank transaction scales in the financial network. In 2017, the number of interbank connections among financial institutions rose dramatically as compared to 2014 . It is apparent from the graph that the range of intense connections in 2017 is larger than that in 2014, indicating that more financial institutions have shown higher interconnection levels in 2017. In 2014, China Development Bank (CDB), Bank of China (BOC), Industrial and Commercial Bank of China (ICBC) and Agricultural Bank of China (ABC) had bigger interbank transaction scales than other institutions. Meanwhile, Industrial Bank, Minsheng Bank, Bank of Communications and Postal Savings Bank play significant roles in the interbank market. In 2017, CDB and ICBC became more significant while other commercial banks, including $\mathrm{BOC}, \mathrm{ABC}$ and China Construction Bank (CCB) became relatively less interconnected in the interbank network. More banks have expanded their inter-bank lending and connections among financial institutions.

\subsection{Results of degree centralities}

The centralities of more than 200 financial institutions have been determined, as illustrated in Figure 3- (a)-(d). The $x$-axis represents the financial institutions in the network [3]. Overall, there is no discernible difference between Degree centrality, Betweenness, and PageRank. Each year, the degree of centrality of each financial institution varies widely. For example, the degree centrality of China Huarong Asset Management Co., Ltd. was 39 in 2014, but it reached as high as 200 in 2017. The degree value at China Guangfa Bank fell from 157 in 2014 to 69 in

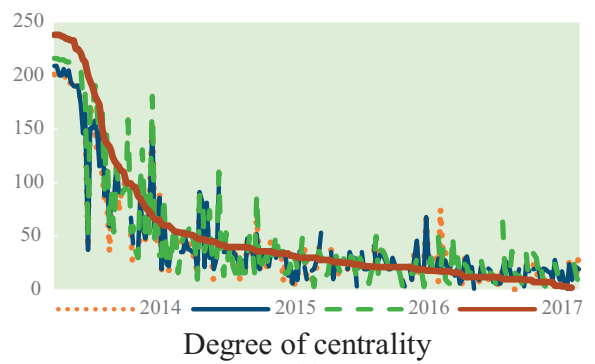

(a)

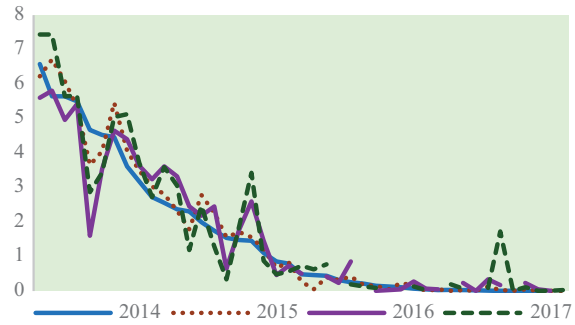

Degree of Betweeness centrality

(c)

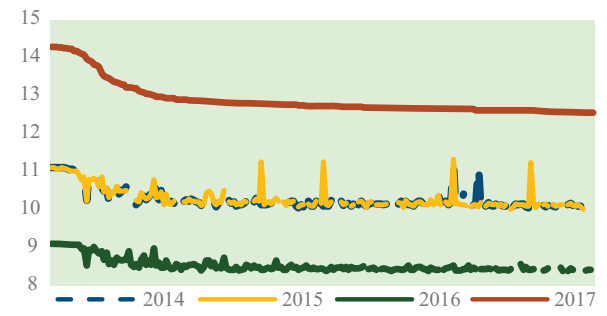

Degree of closeness centrality

(b)

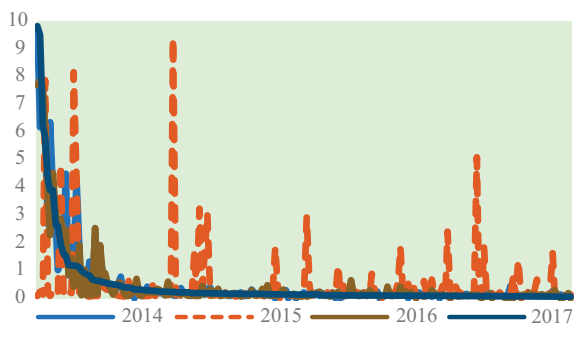

Degree of PageRank centrality

(d)
Figure 3.

(a): Degree of centrality (b): Degree of closeness centrality (c): Degree of Betweeness centrality (d): Degree of PageRank centrality 
$\mathrm{K}$

51,13

70

2017. This result is in line with Huang et al. (2017) . Degree, Betweenness and PageRank centrality have shown similar power-law distribution tendencies, with degree $k$ being proportional to $k^{-\gamma}$ (indicates a power exponent). It also suggests that the interconnection network has a scale-free network structure (Kanno, 2015; Hausenblas et al., 2015). There is, however, a minor variation in closeness centrality, and the value climbed dramatically from 2016 to 2017. It indicates that different financial institutions have the same level of farness to borrow funds, and it was easier to access fund in 2017. The top 100 institutions' degree centrality accounted for $81.9 \%$ of all institutions. The top 20 institutions' PageRank centrality accounted for $66.5 \%$ value, showing that the top 20 big financial institutions had significant effects on other institutions in the network.

\subsection{Results for Linear Granger-causality tests}

Unlike network analysis, which studies the interconnection of financial institutions from the perspective of interbank lending, granger causality test examines the connection among financial institutions from the perspective of stock price volatilities. Figure 4 depicts the granger causality network of financial institutions graphically. The circles indicate

Figure 4.

The Granger-causal relationships among Chinese financial institutions

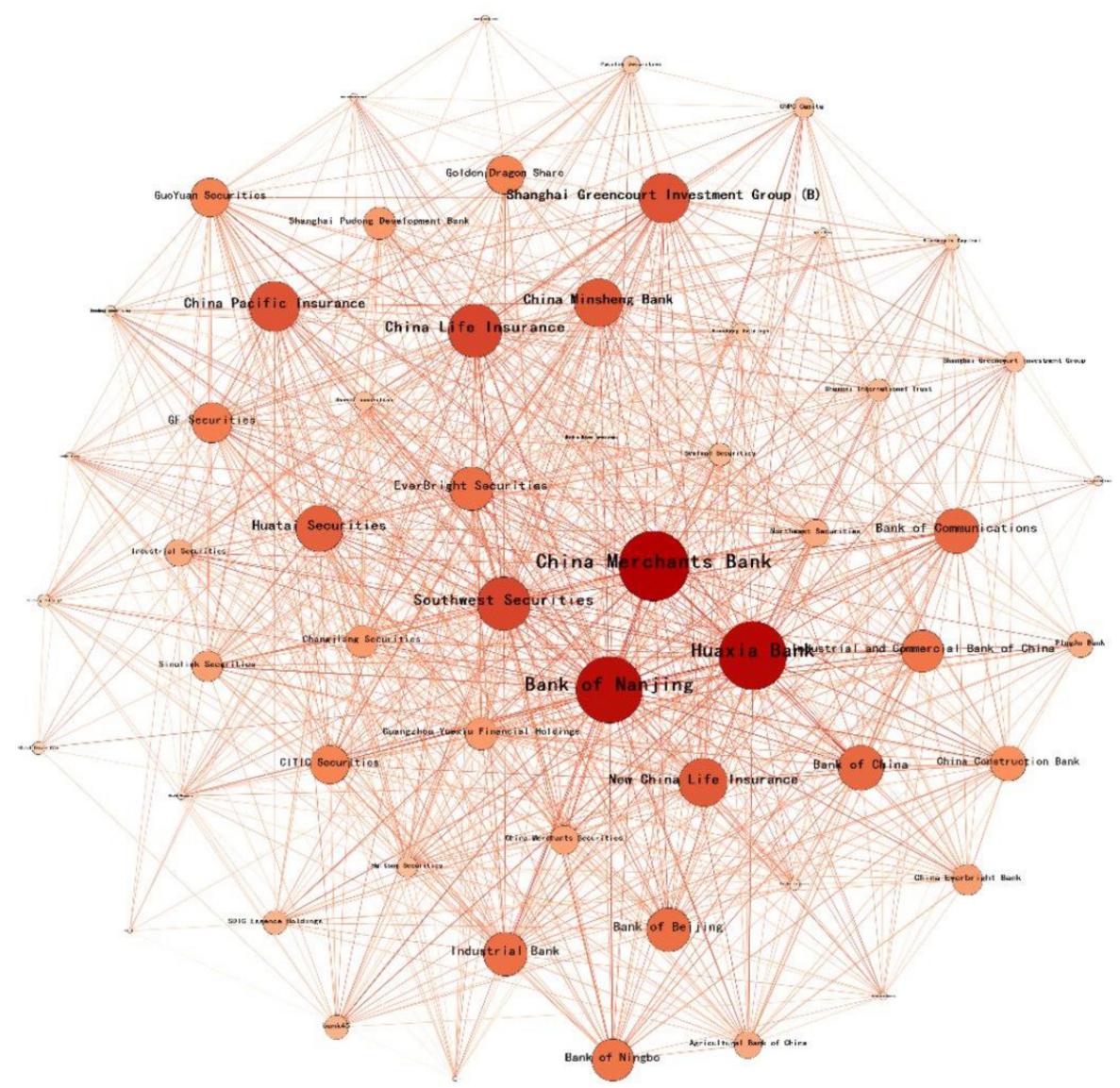


58 financial institutions in China. The straight lines show the Granger-causal connections among institutions. In order to eliminate heteroskedasticity in series, Generalized Autoregressive Conditional Heteroskedasticity (GARCH $(1,1)$ ) is applied (Billio et al., 2010; Mensah and Premaratne, 2017; Gao and Ren, 2013).

The result indicates that the top five institutions include three commercial banks, one security business, and an insurance firm. The financial industry is still dominated by large state-owned banks like ICBC, CCB, ABC, and BOC. The Financial Stability Board (FSB) has designated ICBC and CCB as global systemically significant banks (G-SIBs). In order to mitigate possible risk exposure, both banks will need an additional $1.5 \%$ capital ratio cushion. Non-state-owned institutions like joint-stock banks, city commercial banks, and insurance companies play a more significant role in the Chinese financial system. Huaxia Bank and Bank of Nanjing have 41 and 40 connections with other institutions, respectively. They are the second and third most interconnected banks in the financial network. Southwest Securities and China Life Insurance have 32 and 31 causality connections, respectively.

Some of the smaller, less well-known institutions have also demonstrated strong ties with others. After 2010, China saw a marketization and deregulation trend. The economic expansion and risk-taking activities make non-state-owned institutions tend to be more active in the interbank market for fund raising. Therefore, the financial stability of non-stateowned institutions merits greater attention [4]. Table 1 displays the descriptive information on financial institution interconnections.

The results indicate that banks have the greatest number of interconnections, followed by insurance companies, securities companies and other institutions. Larger institutions tend to have more interconnections with others. Banks have demonstrated more connections than other institutions. The government provides policy leaning to stateowned banks, which function as wholesale banks in China's credit-driven economy. The credit line is regarded as a key factor in influencing the behavior of customers and the asset prices, such as housing price (Qi et al., 2016; Dospinescu et al., 2019; Su et al., 2021). Because of the large volume of money transactions, state-owned banks play the most crucial role in the financial system. On the other hand, insurance companies are taking a more active part in the market than securities. Dynamic Causality Index (DCI) is used to calculate the level of interconnectedness in a system and makes it possible to compare systems with a different number of institutions. According to Mensah and Premaratne (2017), DCI can be defined as follows:

$$
\mathrm{DCI}=\frac{\text { number of causal relationships during research period }}{\text { number of total possible causal relationships }}
$$

The average DCI value is 0.141 between 2012 and 2018, which is less than the value between 2008 and 2011.The findings indicate that the DCI value of all listed financial institutions between 2012 and 2018 is 0.14 , which is significantly lower than the value between 2008 and 2011 by Gao and Ren (2013). It indicates that the Granger causality among Chinese financial institutions shows a downward trend after the financial crisis and the weak connection of asset prices. This result can be attributed to the fact that. First; The impact of the financial crisis in China and globally becomes weak, which made the systemic risk faced by financial institutions decrease. The reduction in the pressure coming from the whole system caused the interconnection of the asset price decrease. Second,more non-bank financial institutions are widely involved in the system after 2012. They provide more transaction choices for individual institutions. Since the interbank lending channel is not restricted to banks any more, more non-bank institutions began to provide liquidity to the system. The expansion of the system scale promotes the reduction of DCI. The increased market size dilutes the systemic risk caused by the interconnection of asset prices. 
$\mathrm{K}$

51,13

Mensah and Premaratne (2017) argued that Asia's (excluded China mainland) financial system becomes more densely connected during a financial crisis. Our findings corroborate this result and reveals a downward trend in interconnectedness among Chinese financial institutions after the financial crisis. The lower level of interconnectedness compared to other Asian areas can be linked to the fact that more non-bank financial institutions are broadly integrated into the system, allowing more transaction options for individual institutions. Since the interbank lending channel is not restricted in banks, more non-bank institutions began to provide liquidity to the system which reduced the DCI value. Because the interbank lending channel is open to non-bank institutions, more non-bank institutions begin to provide liquidities to the system. Compared with other regions, the DCI is about 0.21 and 0.12 in Southeast Asia and Asia, respectively, from 2012 to 2014 (Hamilton, 2015; Mensah and Premaratne, 2017). On the other hand, the DCI for the worldwide financial system, comprising banks, hedge funds, and insurance institutions, was roughly 0.13 in 2018 (Billio et al., 2012). It shows that the Chinese financial system is marginally more integrated than the rest of the globe and Asia, but much less than Southeast Asia over the same period.

\subsection{Results for SII and VI}

The interconnectedness can evaluate the possibility of an institution to be affected when the systemic risk arises, but cannot measure the consequence of the risk quantitatively. The potential loss of an institution is an important measure when the risk is spreading. The tail risk, which measures the risk of individual institution and the whole system, is useful to evaluate the intensity of risk contagion. The results of four types of institutions are listed in Table 2. All banks are expected to have an SII of approximately 10. It means that if one bank fails, nearly ten more institutions will fail as a result. The VI values vary from 0.2565 to 0.2771 . It suggests that another institution will be affected with the probability ranging from $25.65 \%$ to $27.71 \%$ when a bank fails. The similar VI and SII statistics show that all banks in China have comparable market business practices. However, China Everbright Bank, Bank of Communications, and Huaxia Bank, all of which are not typical large state-owned banks, rank the first, second and fifth in terms of SII and VI. China Everbright Bank, in particular, becomes the most systemically significant bank in terms of the SII and VI indexes. This can be attributed to joint-stock banks' aggressive business approach, given they have fewer assets than large state-owned banks. A proactive company strategy generally entails more market linkages and interactions. The most susceptible banks include China Everbright Bank, China Construction Bank, Agricultural Bank of China, and Bank of Communications. Three of them are state-owned banks, indicating that the bank size has a considerable influence in determining the vulnerability. One factor might be that state-owned banks are increasingly involved in sophisticated financial transactions.

Huang (2017) examines the tail risk measures of Chinese listed banks between 2007 and 2014 , and argues that the SII values are between 8.56 and 9.48. However, the SII values in our analysis range between 9.33 and 10.46, which are higher than that of Huang (2017) [5]. It reveals that the systemic risk in China's financial sector keeps a downward trend. On the other hand, Zhou (2010) investigates 28 listed banks in the US between 1987 and 2008, and finds that the SII values range between 6.53 and 12.44, which is lower than the value of Chinese banks. It can be attribute to the fact that the Chinese banking industry is more concentrated than the United States and other industrialized countries. As a result, the impact of systemic risk is greater than the findings of Huang (2017). This observation is consistent with the Granger Causality result.

The peak VI value for all banks between 2012 and 2018 is $27.71 \%$, substantially lower than the amount between 2007 and 2014 [6]. One possible cause is that the financial crisis in 2008 heightened the systemic risks of financial institutions as a whole. Banking sector was 


\begin{tabular}{|c|c|c|c|c|c|c|}
\hline Type & Name & SII & SII rank & VI & VI rank & Intercon- \\
\hline \multirow[t]{16}{*}{ Banks } & China Everbright Bank & 10.46 & 1 & 0.2771 & 1 & 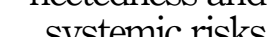 \\
\hline & Bank of Communications & 10.40 & 2 & 0.2771 & 1 & \\
\hline & Agricultural Bank of China & 9.99 & 4 & 0.2771 & 1 & \\
\hline & China Construction Bank & 9.74 & 6 & 0.2771 & 1 & \\
\hline & Huaxia Bank & 10.27 & 3 & 0.2755 & 5 & \\
\hline & Bank of China & 9.90 & 5 & 0.2755 & 5 & \\
\hline & Industrial Bank & 9.70 & 8 & 0.2687 & 7 & 73 \\
\hline & Bank of Nanjing & 9.54 & 10 & 0.2687 & 7 & \\
\hline & Industrial and Commercial Bank of China & 9.48 & 11 & 0.2653 & 9 & \\
\hline & Bank of Ningbo & 9.44 & 12 & 0.2653 & 9 & \\
\hline & PingAn Bank & 9.16 & 15 & 0.2635 & 11 & \\
\hline & Shanghai Pudong Development Bank & 9.70 & 7 & 0.2600 & 12 & \\
\hline & China Merchants Bank & 9.58 & 9 & 0.2583 & 13 & \\
\hline & China CITIC Bank & 9.41 & 13 & 0.2583 & 13 & \\
\hline & China Minsheng Bank & 9.16 & 16 & 0.2565 & 15 & \\
\hline & Bank of Beijing & 9.33 & 14 & 0.2512 & 16 & \\
\hline \multirow[t]{26}{*}{ Security Companies } & Soochow securities & 16.91 & 1 & 0.2853 & 1 & \\
\hline & GF Securities & 16.61 & 6 & 0.2848 & 2 & \\
\hline & Northeast Securities & 16.89 & 2 & 0.2837 & 3 & \\
\hline & Changjiang Securities & 16.79 & 3 & 0.2837 & 3 & \\
\hline & EverBright Securities & 16.76 & 4 & 0.2837 & 3 & \\
\hline & Industrial Securities & 16.61 & 7 & 0.2837 & 3 & \\
\hline & China Merchants Securities & 16.53 & 8 & 0.2837 & 3 & \\
\hline & Huatai Securities & 16.48 & 9 & 0.2832 & 8 & \\
\hline & Pacific Securities & 16.19 & 12 & 0.2826 & 9 & \\
\hline & Southwest Securities & 16.00 & 15 & 0.2821 & 10 & \\
\hline & Shanxi securities & 15.75 & 16 & 0.2821 & 10 & \\
\hline & CITIC Securities & 16.73 & 5 & 0.2816 & 12 & \\
\hline & GuoYuan Securities & 16.08 & 13 & 0.2816 & 12 & \\
\hline & Haitong Securities & 16.31 & 10 & 0.2810 & 14 & \\
\hline & Founder Securities & 16.06 & 14 & 0.2805 & 15 & \\
\hline & Sinolink Securities & 15.68 & 17 & 0.2805 & 15 & \\
\hline & Shanghai Greencourt Investment Group & 13.32 & 20 & 0.2805 & 15 & \\
\hline & Harbin Hatou Investment & 13.69 & 19 & 0.2800 & 18 & \\
\hline & Sealand Securities & 16.19 & 11 & 0.2794 & 19 & \\
\hline & Shanghai Greencourt Investment Group & 12.25 & 24 & 0.2773 & 20 & \\
\hline & SDIC Essence Holdings & 13.89 & 18 & 0.2767 & 21 & \\
\hline & Shanghai Chinafortune & 12.46 & 23 & 0.2751 & 22 & \\
\hline & Guangzhou Yuexiu Financial Holdings & 13.02 & 21 & 0.2746 & 23 & \\
\hline & Golden Dragon Share & 12.70 & 22 & 0.2718 & 24 & \\
\hline & Polaris Bay Group & 10.46 & 26 & 0.2702 & 25 & \\
\hline & CNPC Capital & 10.73 & 25 & 0.2663 & 26 & \\
\hline 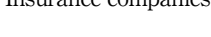 & New Ching I ifo Incurance & 305 & 4 & 02425 & 1 & \\
\hline & China Life Insurance & 3.12 & 1 & 0.2396 & 2 & \\
\hline & China Pacific Insurance & 3.10 & 2 & 0.2396 & 2 & \\
\hline & PING AN Insurance & 3.08 & 3 & 0.2316 & 4 & \\
\hline & Xishui Strong Year & 2.23 & 5 & 0.1462 & 5 & \\
\hline & Biocause Pharmaceutical & 1.65 & 6 & 0.1043 & 6 & \\
\hline \multirow{10}{*}{$\begin{array}{l}\text { Other financial } \\
\text { companies }\end{array}$} & Shaanxi International Trust & 4.85 & 1 & 0.2776 & 1 & \\
\hline & Shanghai AJ Group & 4.62 & 2 & 0.2712 & 2 & \\
\hline & Anxin Trust & 4.53 & 3 & 0.2671 & 3 & \\
\hline & Xinli Finance & 4.23 & 5 & 0.2618 & 4 & \\
\hline & Hainan Haide Industry & 4.23 & 6 & 0.2612 & 5 & \\
\hline & Panda Fireworks Group & 4.10 & 8 & 0.2593 & 6 & \\
\hline & Minsheng Holdings & 4.29 & 4 & 0.2575 & 7 & Table 2. \\
\hline & Minmetals Capital & 4.13 & 7 & 0.2569 & 8 & SII and VI for financial \\
\hline & Rendong Holdings & 3.95 & 10 & 0.2563 & 9 & institutions grouped \\
\hline & Kunwu Jiuding Investment Holdings & 4.05 & 9 & 0.2508 & 10 & in types \\
\hline
\end{tabular}


$\mathrm{K}$

51,13

highly concerned by regulator after the crisis due to its vulnerability. Risks began to be decreased as a result of stricter controls imposed by supervisors. In general, bank VI varies year to year, but the risk resistance capacity of Chinese banking sector continues to improve. Some relatively small banks are showing better performance in risk mitigation. For example, China Merchants Bank (CMB), a joint-stock bank, hit the highest VI value of $36.29 \%$ within all banks during 2007 and 2014 (Huang, 2017). However, between 2012 and 2018, the value fell to $25.83 \%$, ranking the 13th among all banks. China Construction Bank (CCB), a giant stateowned bank, had the highest VI value constantly. This finding suggests that big state-owned banks are still more vulnerable to financial market shocks compared with other banks. It validates existing domestic policies that impose stricter control on major banks, such as more significant reserve requirements or other macroprudential oversight [7]. Meanwhile, big state-owned banks, i.e. China Construction Bank, Bank of China, Agricultural Bank of China, and Industrial and Commercial Bank of China, have been classified as Global Systemically Important Banks (G-SIBs) from 2019. Additional 1\% or 1.5\% surcharge capital buffer will be applied to these banks. Future requirement such as Total Lost Absorb Capability (TLAC) is imposed. This indicates that the potential high systemic risks of big state-owned banks have received concern by both domestic and international regulators.

Another notable characteristic is that security companies have considerably higher SSI values than other financial institutions, indicating that they have a high systemic risk exposure in the financial system. Theoretically, the higher the level of interconnectedness, the larger the expected loss of financial institutions. Security companies have fewer interconnections in the market due to their modest size. Their potential losses, however, are expected to be greater than those of banks. This finding is consistent with Hsu et al. (2014) which suggested that security firms face higher systemic risks than banks and insurance businesses in China. It can be attributed to the fact that security companies have witnessed fast growth due to bank-security collaboration, which offers a channel for banks to transfer funds outside of the balance sheet through various asset management programs. As a result, in 2012, it became the primary component of China's shadow banking businesses (Gao and Wang, 2014).

Therefore, security companies are more involved in financial innovation, while banks, especially giant banks, are strictly supervised by the regulator. As shown in Table 2, Soochow securities hits the highest SII and VI values in the security sector. It is a small security company based in the Yangtze River Delta, the most developed area in China.

The intensive capital flow in this region makes Soochow securities act more aggressive than other institutions. CNPC Capital and Polaris Bay Group, on the other hand, have the lowest systemic risks among security firms. The CNPC Capital, which is invested by a statedowned enterprise, provides financial services to the parent company. As a result, it has relatively fewer connections in financial system than other financial institutions. Polaris Bay Group, a local security firm, is headquartered in Hebei Province, where economic development is not as fast as than in other Chinese regions. The geographical factor has significantly limited the interconnections with other institutions.

Finally, the group of insurances companies has the lowest impact on other financial institutions, since all insurance companies have lower VI values than other institutions. One possible explanation is the relative abundance of fund makes insurance companies bear lower systemic risks. Considering the lower level of interconnection, other financial institutions have higher VI values than insurance companies, but still lower than banks and security companies.

\subsection{Results of statistical measures}

It is distinct to observe the trend of statistical measures, i.e. Value of Risk (VaR), CoVaR, and DCVaR, of different types of financial institutions from 2012 to 2018, as shown in Table 3. 
Table 3. $\mathrm{VaR}, \mathrm{CVaR}$ and $\mathrm{DCVaR}$ of different types of financial institutions (in \%) 
$\mathrm{K}$

51,13

76

The results indicate that banks have the lowest VAR among all types of financial institutions. Security and insurance companies have greater VAR values than banks. The group of other financial institutions suffers the highest VAR value, indicating that under-regulated financial institutions may suffer even greater losses when a risk happens [8]. Considering the contagion of potential risks in the financial system, other institutions with low levels of regulations may bring about higher extreme loss and suffer the whole system. Therefore, these institutions deserve more attention from regulators. On the other hand, there is slight difference in CVaRs among different types of financial institutions. Security companies suffer higher DCVaR values than all other kinds of institutions. This is because they are more involved in the financial innovation and shadow banking business, which provide more funds to large and state-owned enterprises. However, the quick large-scale spread of financial innovation may mismatch between the virtual and real economies, increasing systemic risk and undermining the financial system's stability (Feng, 2015; Tan, 2017). Due to the volume of transactions between security businesses and other institutions, the risk has swiftly transferred from security companies to other financial sectors.

Table 3 shows that all statistical measures, i.e. VaR, CVaR, and DCVaR, increased significantly from 2012 to 2014 and peaked in 2015. In the same year, the Chinese stock market suffered a major drop in prices. China's stock markets saw abnormally high volatility from June to August 2015. In 53 trading days, the Shanghai Composite Index plummeted by more than $45 \%$, from 5,178 points to 2,851 points. The stock market value quickly dwindled, from a high of 5,178 on June 12, 2015, to a low of 2,850 points on August 26, 2015. The total market value of the Shanghai and Shenzhen markets evaporated by about 33 trillion yuan. The severe capital market crash transferred risk to other institutions and raised risk measures of the whole financial system. The stock market progressively recovered till the end of 2015, and the financial market progressively stabilized over the next few years. Insurance and security firms, in general, contribute more to systemic risk. But other institutions, such as trust funds, financial companies, etc. may bring about severe loss and endanger the financial system as a whole. The mean value of $\Delta \mathrm{CoVaR}$ of Chinese listed banks is lower than 166.9 between 2007 and 2014, compared with Huang (2017). It suggests that, from the standpoint of VAR, the systemic risk of Chinese banking sector is decreasing. Adrian (2016) investigates the $\Delta \mathrm{CoVaR}$ of 1,226 US financial institutions between 1986 and 2010, and discovers a value of 120. It means the systemic risks of Chinese banks are similar with US banks, from the perspective of VAR (see Table 4)

The measures of MES and LRMES exhibit a similar trend with VaR and CVaR. the MES and LMES values of banks are the lowest among all types of financial institutions. The values of security companies are higher than other types of institutions. This result demonstrates that banks contributes less than other kinds of institutions, while security companies are the major contributor to the systemic risks. Both measures keep increasing from 2012 to 2015, and reach the peak values in 2015. After that, a decreasing trend is observed for all kind of

\begin{tabular}{lcccccccr}
\hline & \multicolumn{2}{c}{ Bank } & \multicolumn{2}{c}{ Security } & \multicolumn{2}{c}{ Insurance } & \multicolumn{2}{c}{ Others } \\
Year & MES & LRMES & MES & LRMES & MES & LRMES & MES & LRMES \\
\hline 2012 & 1.739 & 0.285 & 3.541 & 0.481 & 3.003 & 0.454 & 3.176 & 0.405 \\
2013 & 2.818 & 0.384 & 3.631 & 0.453 & 3.154 & 0.436 & 3.199 & 0.375 \\
2014 & 2.138 & 0.370 & 3.009 & 0.459 & 2.637 & 0.449 & 2.432 & 0.355 \\
2015 & 3.827 & 0.339 & 5.679 & 0.432 & 4.326 & 0.376 & 3.208 & 0.225 \\
2016 & 1.775 & 0.294 & 3.852 & 0.502 & 2.760 & 0.421 & 3.059 & 0.370 \\
2017 & 1.193 & 0.343 & 1.862 & 0.451 & 1.869 & 0.487 & 1.580 & 0.321 \\
2018 & 1.832 & 0.314 & 2.647 & 0.396 & 2.786 & 0.447 & 2.107 & 0.277 \\
\end{tabular}

Table 4.

the MES and LRMES of 4 types of financial institutions
2018 
institutions. This result confirms our analysis above, when the economy expands, the systemic risk of all financial institutions is heavily accumulated. However, when the stock market crash, the systemic risks of all financial institutions begin to release quickly. It proves the existence of pro-cyclical effect between the financial risk and the stock market. According to $\mathrm{Xu}$ et al. (2020), the hot listing market is the result of governmental subsidies and the removal of entry restrictions in the junior market, the profitability of listed firms depends on the combination of stockholder's equity, long-term liabilities, provisions and deferred revenues positively. The effective supervision on capital markets can lower the systematic risk of the whole financial market. On the other hand, the early warning system of financial bubbles is crucial to prevent the contagion of systemic risks in the system.

\section{Conclusions and discussions}

The global financial system is concerned about systemic risks and the financial system's stability as a result of the financial crisis. As the world's second-largest market, China's financial sector has gotten much attention in recent years. Financial institutions grow increasingly diverse as a result of economic change and a succession of liberalization initiatives. Financial firms and banks, security businesses, insurance companies, and trusts all play an essential part in the market. Cooperation among financial institutions and financial innovations has resulted in tremendous growth in depth and breadth, boosting risk contagion throughout the network.

The financial crisis has raised the concern of systemic risks and the stability of the financial system around the globe. As the second-largest market in the world, the Chinese financial system has drawn growing attention in recent years. Financial institutions grow increasingly diverse as a result of economic change and a succession of liberalization initiatives. Banks, security companies, insurance companies, trusts, financial companies all play significant roles in the market. The transactions among financial institutions and the development of financial innovations have promoted the role of non-bank financial institutions in the financial network. Through the complex financial network, non-bank financial institutions will transmit risks to other institutions through various channels. Therefore, in order to improve the stability of the financial system, it is necessary to bring the systemic importance of non-bank institutions into the scope of supervision. Employing topology analysis, the interconnectedness of the Chinese financial system is investigated. The findings show that big banks are more interconnected and have the largest scales of interbank transactions in the financial network. In 2017, the number of interbank connections among financial institutions rose dramatically as compared to 2014. As a result, more financial institutions demonstrated higher degrees of interconnection in 2017.

Chinese financial system is marginally more integrated than the rest of the globe and Asia, but much less than Southeast Asia during the same period. Institutions that are larger in size tend to have more links with others. Banks have the most interconnections, followed by insurance companies, financial firms, and other organizations. Furthermore, different methods, including Linear Granger, Systemic impact index (SII) and vulnerability index (VI), CoVaR, and MES, are used to assess the level of systemic risks of four categories of Chinese financial institutions. The results show that insurance and security firms contribute significantly more to systemic risk. Because of their size, giant state-owned banks may face more risks. Security companies have significantly higher values of SSI than other financial institutions, which indicates that they hold higher systemic risk exposure in the financial system. In other words, they are the major contributor to systemic risks. Considering high systemic risks, regulators should also pay attention to the small and medium sized security companies, and carry out targeted macro-prudential supervision on both large securities companies and small and medium-sized securities. Other institutions, such as trusts, financial 
$\mathrm{K}$

51,13

78

companies, etc., may bring about severe loss and jeopardize the financial system as a whole. The potential losses of other financial institutions are expected to be greater than those of banks, insurance, and securities. Therefore, the regulator needs to impose the supervision not only on systemic important banks, but also on important insurance, securities, and other financial institutions, in order to reduce the contagion effect of systemic risks within the financial system. From 2012 to 2014, all statistical metrics showed a significant increasing trend, peaking in 2015, when the Chinese stock market saw a considerable decrease in prices. A considerable policy conclusion is that other non-banks, non-security and non-insurance financial institutions deserve more attention from regulators considering the contagion of potential risks in the financial system. In order to strengthen the financial system's stability, stronger nationwide supervision of these financial institutions is required. In addition, the improvement of the capital market may effectively lessen the systemic risk of the whole market.

Finally, it is necessary to indicate that the systemic risk might be overestimated since the RAS algorithm simulates the bilateral exposure matrix. Actual bilateral exposure is helpful to assess the systemic risk. Further, we estimate the potential system risk based on the stock price co-movements. The generation mechanism and contagion process of systemic risk is not discussed. An alternative approach is to investigate the risk propagation from the perspective of network contagion theory. Using this method, further research can reveal the contagion process of systemic risk and the extent to which a shock can lead to risk propagation within the financial system.

\section{Notes}

1. The Banks and insurance companies are supervised by China Banking and Insurance Regulatory Commission. Securities, fund companies, future companies, and trust companies are supervised by China Securities Regulatory Commission.

2. Take the micro-credit companies as instance, there are 8,965 micro-credit companies in 2015, according to the statistics of People's Bank of China. Then it follows a consecutive decreasing trend of total numbers of micro-credit companies, there are only 7,118 micro-credit companies in 2019. More than 20 percent of micro-credit companies are withdrawn from the market. Meanwhile, there are 5,937 financial guarantee companies in 2019, while the number was 8,590 in 2012. It means over 30 percent financial guarantee companies are in distress and withdrawn from the market. We believe the small institutions, which are not regulated by the central supervisor, may bear higher risks than banks, securities and insurance which are regulated by the national supervisor. Since all institutions are taking part in the interbank transactions, the risk can be propagated in the financial network and lead to the systemic risk.

3. In order to make the graph clear and readable, the $x$ axis labels, i.e. the names of all institutions, are hidden in Figure 3 (a)-(d). The out-degree and out-clonessness degree are used to represent the degree centrality and clonessness centrality, respectively.

4. Due to the serious credit risk, Baoshang Bank has already been announced to go bankruptcy since March 2021. The interbank cost is pushed up for some smaller lenders. The central bank inject cash into the banking system in order to prevent contagion risks. (Reuters reports)

5. It is also necessary to indicate that the SII index is related to the number of institutions in the network. 14 financial institutions are involved in the work by Huang (2017) and there are 16 financial institutions in our sample. However, the value of VI is not affected by the number of institutions, which makes it suitable for the cross-time and cross-group analysis and comparison.

6. Huang (2017) shows that all VI values of banks are higher than 33\% from 2007 to 2014.

7. In 12th Jan, 2010, China central bank started to increase banks' reserve requirement ratio until the middle of 2011 . For large banks, the reserve requirement ratio increased from $15.5 \%$ to $21.5 \%$. Correspondingly, the ratio raised from $13.5 \%$ to $19.5 \%$ for other banks. After that People's Banks of 
China gradually relaxed the reserve requirement. In 2018, it returned to original level in the beginning of 2010 . There are always $2 \%$ additional reserve requirement for large banks in order to improve its risk resistant ability. Moreover, recent new regulatory measure: targeted reserve requirement ratio cuts started in 2018 also set the ratio of joint-stock banks and foreign-invested banks $2-3 \%$ lower than large state-owned banks. In order to improve the regulatory framework for systemically important financial institutions, People's Bank of China and the China Banking and Insurance Regulatory Commission release of a draft to solicit public opinions on the measures for the evaluation of systematically important banks In December 2019. The measures will be the basis for the identification of systemically important banks in China, according to a statement jointly issued by the two departments.

8. Banks, Insurance companies and securities are regulated by national regulation commissions, i.e. China Banking and Insurance Regulatory Commission, China Securities Regulatory Commission. However, other types of financial institutions, such as Trusts, Financial companies, etc. are regulated by local regulators. The supervision intensity is not as strong as national regulators.

\section{References}

Acharya, V., Pedersen, L., Philippon, T. and Richardson, M. (2010), Measuring Systemic Risk, Working Paper, Federal Reserve Bank of Cleveland.

Adrian, T. and Brunnermeier, M.K. (2016), "CoVaR”, American Economic Review, Vol. 106 No. 7, pp. 1705-1741.

Amalia, A. (2018), "Systemic risk: a review", The International Journal of Business and Management, Vol. 6 No. 6, pp. 228-235.

Billio, M., Getmansky, M., Lo, A. and Pelizzon, L. (2010), "Econometric measures of systemic risk in the finance and insurance sectors", NBER Working Paper, p. 16223.

Billio, M., Getmansky, M., Lo, A.W. and Pelizzon, L. (2012), "Econometric measures of connectedness and systemic risk in the finance and insurance sectors", Journal of Financial Economics, Vol. 104 No. 3, pp. 535-559.

Bisias, D., Flood, M., Lo, A.W. and Valavanis, S. (2012), “A survey of systemic risk analytics”, Annual Review of Financial Economics, Vol. 4 No. 1, pp. 255-296.

Brnardi, M., Maruotti, A. and Petrella, L. (2017), "Multiple risk measures for multivariate dynamic heavy-tailed models", Journal of Empirical Finance, Vol. 43, pp. 1-32.

Brownlees, C. and Engle, R.F. (2016), "SRISK: a conditional capital shortfall measure of systemic risk", Review of Financial Studies, Vol. 30 No. 1, pp. 48-79.

Brunnermeier, M.K. and Pedersen, L.H. (2009), "Market liquidity and funding liquidity", The Review of Financial Studies, Vol. 22 No. 6, pp. 2201-2238.

Caccioli, F., Shrestha, M., Moore, C. and Farmer, J.D. (2014), "Stability analysis of financial contagion due to overlapping portfolios", Journal of Banking and Finance, Vol. 46, pp. 233-245.

Censor, Y. and Zenios, S.A. (1998), Parallel Optimization: Theory, Algorithms, and Applications, Oxford University Press, New York.

De Haan, L. and Ferreira, A. (2006), "Extreme value theory”, Springer Series in Operations Research and Financial Engineering.

De-Bandt, O. and Hartmann, P. (2020), Systemic Risk: A Survey, ECB Working Paper, Vol. 35.

Dospinescu, O., Anastasiei, B. and Dospinescu, N. (2019), "Key factors determining the expected benefit of customers when using bank cards: an analysis on millennials and generation $Z$ in Romania”, Symmetry, Vol. 11 No. 12, p. 1449. doi: 10.3390/sym11121449.

Drakos, A.A. and Kouretas, G.P. (2015), "Bank ownership, financial segments and the measurement of systemic risk: an application of CoVaR", International Review of Economics and Finance, Vol. 40, pp. 127-140.

European Central Bank (2009), Financial Stability Review, 12, Frankfurt Am Main. 
$\mathrm{K}$

51,13

80

Feng, J. (2015), "Research on shadow bank and the impact on financial security of China", in Zhang, R., Zhang, Z., Liu, K. and Zhang, J. (Eds), LISS 2013, Springer Publisher, Berlin, Heidelberg.

Gao, B. and Ren, R. (2013), "Measuring systemic importance of financial institutions based on grangercausality network model", Management Review, Vol. 25 No. 6, pp. 10-58, (in Chinese).

Gao, S. and Wang, Q. (2014), "Chasing the shadow in different world: shadow banking and its regulation in the US and China", Manchester Journal of International Economic Law, Vol. 11, p. 421.

Girardi, G. and Tolga Ergün, A. (2013), "Systemic risk measurement: multivariate GARCH estimation of CoVaR", Journal of Banking and Finance, Vol. 37 No. 8, pp. 3169-3180.

Granger, C.W. (1969), "Investigating causal relations by econometric models and cross-spectral methods", Econometrica, Vol. 37 No. 3, p. 424.

Hamilton, D., Hughes, T. and Malone, S.W. (2015), "Measuring systemic risk in the Southeast asian financial system”, Moody's Analytics Risk Perspectives, Risk Data Management.

Hausenblas, V., Kubicová, I. and Lešanovská, J. (2015), "Contagion risk in the Czech financial system: a network analysis and simulation approach", Economic Systems, Vol. 39 No. 1, pp. 156-180.

Hsu, P.H., Tian, X. and Xu, Y. (2014), "Financial development and innovation: cross-country evidence", Journal of Financial Economics, Vol. 112 No. 1, pp. 116-135.

Huang, Q., De Haan, J. and Scholtens, B. (2017), “Analysing systemic risk in the Chinese banking system”, Pacific Economic Review, Vol. 24 No. 2, pp. 348-372.

Ji, Q., Bouri, E., Roubaud, D. and Shahzad, S.J. (2018), "Risk spillover between energy and agricultural commodity markets: a dependence-switching CoVaR-copula model", Energy Economics, Vol. 75 No. 1, pp. 14-27.

Kanno, M. (2015), "The network structure and systemic risk in the Japanese interbank market", Japan and the World Economy, Vol. 36 No. Nov, pp. 102-112.

Kiyotaki, N. and Moore, J. (1997), "Credit cycles”, Journal of Political Economy, Vol. 105 No. 2, pp. 211-248.

Kritzman, M., Page, S. and Turkington, D. (2010), "Defense of optimization: the fallacy of 1/N", Financial Analysts Journal, Vol. 66 No. 2, pp. 31-39.

Li, X., Yu, H., Fang, L. and Xiong, C. (2019), "Do firm-level factors play forward-looking role for financial systemic risk: evidence from China”, Pacific-Basin Finance Journal, Vol. 57, p. 101074.

Longstaff, F.A. (2010), “The subprime credit crisis and contagion in financial markets”, Journal of Financial Economics, Vol. 97 No. 3, pp. 436-450.

Lopez-Espinosa, G., Moreno, A., Rubia, A. and Valderrama, L. (2015), "Systemic risk and asymmetric responses in the financial industry", Journal of Banking and Finance, Vol. 58, pp. 471-485.

Mainik, G. and Schaanning, E. (2014), "On dependence consistency of CoVaRand some other systemic risk measures”, Statistics and Risk Modeling, Vol. 31 No. 1, pp. 49-77.

Martínez-Jaramillo, S., Pérez, O.P., Embriz, F.A. and Dey, F.L. (2010), "Systemic risk, financial contagion and financial fragility", Journal of Economic Dynamics and Control, Vol. 34 No. 11, pp. 2358-2374.

Mensah, J.O. and Premaratne, G. (2017), "Systemic interconnectedness among Asian banks", Japan and the World Economy, Vol. 41, pp. 17-33.

Paltalidis, N., Gounopoulos, D., Kizys, R. and Koutelidakis, Y. (2015), "Transmission channels of systemic risk and contagion in the European financial network", Journal of Banking and Finance, Vol. 61, pp. S36-S52.

Qi, M., Carbó-Valverde, S. and Rodríguez-Fernández, F. (2016), "The diffusion pattern of non-cash payments: evidence from China”, International Journal of Technology Management, Vol. 70 No. 1, pp. 44-57. 
Segoviano Basurto, M.A. and Goodhart, C.A. (2009), "Banking stability measures”, IMF Working Papers, 09, No. 4, p. 1.

Silva, W., Kimura, H. and Sobreiro, V.A. (2017), "An analysis of the literature on systemic financial risk: a survey", Journal of Financial Stability, Vol. 28, pp. 91-114.

Smaga, P. (2014), The Concept of Systemic Risk, Special Papers, (5), Systemic Risk Centre, London School of Economics and Political Science, London.

Støve, B., Tjøstheim, D. and Hufthammer, K.O. (2014), "Using local Gaussian correlation in a nonlinear re-examination of financial contagion", Journal of Empirical Finance, Vol. 25, pp. 62-82.

Su, C.W., Cai, X.Y., Qin, M., Tao, R. and Umar, M. (2021), "Can bank credit withstand falling house price in China?", International Review of Economics and Finance, Vol. 71, pp. 257-267.

Sun, X., Liu, C., Wang, J. and Li, J. (2020), "Assessing the extreme risk spillovers of international commodities on maritime markets: a GARCH-Copula-CoVaR approach", International Review of Financial Analysis, Vol. 68, p. 101453.

Tan, Y. (2017), "The impacts of competition and shadow banking on profitability: evidence from the Chinese banking industry[J]", North American Journal of Economics and Finance, Vol. 42 No. Nov, pp. 89-106.

Tjøstheim, D. and Hufthammer, K.O. (2013), "Local Gaussian correlation: a new measure of dependence", Journal of Econometrics, Vol. 172 No. 1, pp. 33-48.

Trabelsi, N. and Naifar, N. (2017), "Are Islamic stock indexes exposed to systemic risk? Multivariate GARCH estimation of CoVaR", Research in International Business and Finance, Vol. 42, pp. $727-744$.

Upper, C. (2011), "Simulation methods to assess the danger of contagion in interbank markets", Journal of Financial Stability, Vol. 7 No. 3, pp. 111-125.

Wells, S.J. (2004). "Financial interlinkages in the United Kingdom's interbank market and the risk of contagion".

$\mathrm{Wu}, \mathrm{B}$. and He, J. (2014), "Discussion on financial risk contagion mechanism from the perspective of balance of payments", International Forum, Vol. 16 No. 4, pp. 69-72.

Xiao, B., Wang, S., Zhou, X. and Yan, J. (2014), "Debt network, investor behavior and risk of contagion: evidence from Chinese banking sector and real estate industry", Journal of Management Sciences in China, Vol. 17 No. 11, pp. 139-150, (in Chinese).

Xu, Q., Li, M., Jiang, C. and He, Y. (2019), "Interconnectedness and systemic risk network of Chinese financial institutions: a LASSO-CoVaR approach”, Physica A: Statistical Mechanics and Its Applications, Vol. 534, p. 122173.

Xu, W., Zhu, S. and Wu, Z. (2020), "Building a junior stock exchange: lessons from China”, European Business Organization Law Review, Vol. 21 No. 1, pp. 139-170.

Zhou, C. (2010), "Are banks too big to fail? Measuring systemic importance of financial institutions", International Journal of Central Banking, Vol. 6 No. 4, pp. 205-250.

\section{Corresponding author}

Pei Wang can be contacted at: wangpei@cup.edu.cn

For instructions on how to order reprints of this article, please visit our website:

www.emeraldgrouppublishing.com/licensing/reprints.htm

Or contact us for further details: permissions@emeraldinsight.com 